\title{
Paper point of care
}

\section{By Tim Fulmer, Senior Writer}

A team of U.S. researchers has developed a postage stamp-sized diagnostic for hepatotoxicity and has used it to measure liver enzyme levels in human blood samples. ${ }^{1}$ Diagnostics for All has exclusively licensed the device and is running field tests in Vietnam.

Blood tests for monitoring liver status in at-risk individuals receiving tuberculosis (TB) or HIV therapies are a standard practice. ${ }^{2-4}$ In the developing world, however, logistical limitations can make it difficult and costly to monitor therapy-associated hepatotoxicity.

As a result, there is a need for liver toxicity tests that can be rapidly implemented and interpreted in a resource-limited setting and that are affordable, stable and easy to use. ${ }^{5}$

Prior studies have shown that paper-based microfluidic devices are useful for conducting basic enzymatic and immunoassay tests. ${ }^{6-9}$ Such devices require no external pumps, instrumentation or power and are

"A particularly attractive means of doing this is to use a smart phone able to recognize and interpret colorimetric tests. This capability is something we plan to pursue in the next 1-2 years."

- Jason Rolland, Diagnostics for All portable and disposable, making them suitable for use in the developing world. However, the devices have yet to be validated with actual patient samples.

Thus, a team of researchers led by Nira Pollock, Jason Rolland and George Whitesides set out to design a paper-based device that measured liver enzyme levels in blood from patients receiving HIV and/or TB therapy and that required only the unaided eye to detect and interpret results. To do that, they relied on basic microfluidics technology previously developed in Whitesides' laboratory. ${ }^{10,11}$

The study was performed on U.S. patients by U.S. clinicians and researchers.

Pollock is a researcher in the division of infectious diseases at Beth Israel Deaconess Medical Center, associate medical director of the infectious diseases diagnostic laboratory at the Boston Children's Hospital and assistant professor of medicine at Harvard Medical School. Rolland is senior director of research at Diagnostics for All, a not-forprofit that designs low-cost point-of-care tests for use in the developing world. Whitesides is professor of chemistry at Harvard University.

When a drop of whole blood was applied to an opening in the cover of the device, blood cells were retained in the separation membrane while plasma diffused into the other layers and reacted with reagents. That reaction generated a color readout that indicated the presence of aspartate aminotransferase (AST) and alanine aminotransferase (ALT) in the plasma. AST and ALT are two enzymes commonly associated with liver injury.

The intensity of the color readout was optimized to fall within one of three clinically relevant ranges: $<3 \times, 3 \times-5 \times$ and $>5 \times$ normal AST and ALT levels.

The surface of the paper also included three control zones to monitor device performance. The entire test was completed in about 15 minutes.

The researchers next tested their device on 233 blood samples from patients with HIV and TB who had a range of AST and ALT concentrations. The device was $>90 \%$ accurate using both serum and whole-blood samples.

The authors wrote that their method "can ultimately be produced at a very low cost - on the order of $<\$ 0.10$ per test." Current electronic gold standard tests cost $\$ 4$.

Results were published in Science Translational Medicine.

"The paper provides the first published example of clinical tests using paper-based microfluidic devices and provides convincing evidence that the basic premise of paper microfluidics is sound and worth substantial development," said Scott Phillips, assistant professor of chemistry at Pennsylvania State University.

Earlier this year, Phillips, Whitesides and colleagues published in Analytical Chemistry data on a paper-based microfluidic device that measured alkaline phosphatase, AST and total protein levels in nonclinical samples. ${ }^{12}$

In contrast to much previous work in paper-based diagnostics and assays, the authors "considered logistical constraints from the outset in designing their test, including cost factors, device storage and potential user error," said Barry Lutz.

They also "chose to align their test with current clinical practice, which can greatly increase the likelihood of adoption," he added.

Lutz and colleagues Paul Yager and Elain Fu at the University of Washington are developing paper devices for amplified immunoassays and nucleic acid amplification tests, ${ }^{13}$ with the goal of creating methods that "perform sophisticated biochemical tests in a format that is as easy to use as a pregnancy test."

Lutz and Fu are research assistant professors of bioengineering at the University of Washington. Yager is professor and chair of bioengineering at the university.

\section{Good morning, Vietnam}

Kenneth Hawkins, program officer and research scientist in the diagnostics group at PATH (Program for Appropriate Technology in Health), said the next step should be "a field-based study in one of the target markets in the developing world. The results could be very different with a different patient population and when performed by a representative group of operators in the target market."

The color reading of the device "is subjective, and the device's true ability to quantify results must be proven," added Robert Jenison, CTO at Great Basin Corp. "A reader device would help tremendously."

Great Basin is developing a battery-powered instrument for use in the developing world to detect mutations in TB bacteria. 
"It'll be interesting to test the outcome of the assay if each patient is asked to read his or her own result," said Phillips. "The ideal pointof-care device would be one that provides a readout that is sufficiently unambiguous that anyone can read and interpret it."

Earlier this year, Diagnostics for All and Beth Israel partnered with PATH and The Hospital for Tropical Diseases (HTD) in Vietnam to carry out a preliminary study of the paper-based diagnostic, co-corresponding author Pollock told SciBX. "We are evaluating the performance of the diagnostic in finger-stick testing of 600 patients from the HTD HIV clinic," she said.

Initial data are expected in the next few months. The field study results "will provide data on how well local clinicians are able to read and interpret the test. Initial adoption of the test would likely be in patient clinics where the test would be administered by a trained healthcare provider," Pollock added.

"Additional next steps in the work include long-term stability studies and development of quality manufacturing systems at Diagnostics for All for large-scale production of validated lots of the device," said co-corresponding author Rolland.

The researchers also are interested in using companion reader devices, said Rolland. "A particularly attractive means of doing this is to use a smart phone able to recognize and interpret colorimetric tests. This capability is something we plan to pursue in the next 1-2 years," he said.

The findings are covered by patent applications that are exclusively licensed to Diagnostics for All from Harvard.

Fulmer, T. SciBX 5(39); doi:10.1038/scibx.2012.1021

Published online Oct. 4, 2012

\section{REFERENCES}

1. Pollock, N.R. et al. Sci. Transl. Med.; published online Sept. 19, 2012; doi:10.1126/scitrans/med.3003981

Contact: Jason P. Rolland, Diagnostics For All, Cambridge, Mass. e-mail: jrolland@dfa.org

Contact: Nira R. Pollock, Beth Israel Deaconess Medical Center, Boston, Mass.

e-mail: npollock@bidmc.harvard.edu

2. Saukkonen, J.J. et al. Am. J. Respir. Crit. Care Med. 174, 935-952 (2006)

3. Tostmann, A. et al. J. Gastroenterol. Hepatol. 23, 192-202 (2008)

4. McKoy, J.M. et al. Drug Saf. 32, 147-158 (2009)

5. Peeling, R.W. et al. Nat. Rev. Microbiol. 8, S2-S6 (2010)

6. Martinez, A.W. et al. Proc. Natl. Acad. Sci. USA 105, 19606-19611 (2008)

7. Osborn, J.L. et al. Lab Chip 10, 2659-2665 (2010)

8. Khan, M.S. et al. Anal. Chem. 82, 4158-4164 (2010)

9. Dungchai, W. et al. Anal. Chim. Acta 674, 227-233 (2010)

10. Martinez, A.W. et al. Anal. Chem. 82, 3-10 (2010)

11. Martinez, A.W. et al. Anal. Chem. 80, 3699-3707 (2008)

12. Vella, S.J. et al. Anal. Chem. 84, 2883-2891 (2012)

13. Fu, E. et al. Anal. Chem. 84, 4574-4579 (2012)

\section{COMPANIES AND INSTITUTIONS MENTIONED}

Beth Israel Deaconess Medical Center, Boston, Mass. Boston Children's Hospital, Boston, Mass. Diagnostics for All, Cambridge, Mass. Great Basin Corp., Salt Lake City, Utah Harvard Medical School, Boston, Mass. Harvard University, Cambridge, Mass. The Hospital for Tropical Diseases, Ho Chi Minh City, Vietnam PATH, Seattle, Wash.

Pennsylvania State University, College Park, Pa. University of Washington, Seattle, Wash. 